\title{
A DANÇA COMO RECURSO TERAPÊUTICO PARA A MELHORIA DA SAÚDE DE IDOSAS INSTITUCIONALIZADAS DA CIDADE DE FORTALEZA-CE
}

\author{
Leila Maria de Andrade Filgueira1, Aline Veras Morais Brilhantel'1, Laís Duarte de Moraes2, \\ Paula Pamplona Costa Lima1 e José Clerton de Oliveira Martins1 \\ 1Universidade de Fortaleza, Brasil. leila_filgueira@hotmail.com,alineveras@unifor.br paulapamplona@edu.unifor.br \\ clerton@unifor.br \\ 2 Universidade do Minho, Portugal. laishinodalp@gmail.com
}

\begin{abstract}
Resumo. Introdução: Sabemos que o Brasil, antes referido como um país de jovens, está em processo de transição demográfica e apresenta um rápido envelhecimento populacional, no entanto nos deparamos com a discriminação, e escassez de propostas direcionadas para esse público no intuito de favorecer a autonomia. Objetivo: Descrever os benefícios que a prática da dança pode proporcionar, como recurso terapêutico, a idosas institucionalizadas da cidade de Fortaleza/CE. Método: A pesquisa que deu origem a este estudo se utilizou de uma investigação de abordagem qualitativa, apoiada no método da pesquisa-ação, efetuada em um programa interventivo sob a forma de oficina de dança com sete idosas institucionalizadas. Foram realizadas entrevistas semiestruturadas, analisadas através dos operadores do método do Discurso do Sujeito Coletivo (DSC). Resultados: Foram encontradas categorias que revelam que a dança proporciona benefícios tais como: o aumento da disposição física para a realização das atividades da vida diária, a melhoria dos quadros álgicos e o resgate da autoestima. Conclusões: Os dados indicam que a dança pode ser um importante recurso terapêutico para a melhoria da aptidão física do idoso, contribuindo, assim, para um envelhecimento saudável, englobando aspectos físicos e emocionais.
\end{abstract}

Palavras-chave: Envelhecimento; Dança; Corpo; Saúde do idoso.

\section{DANCE AS A THERAPEUTIC RESOURCE FOR IMPROVING THE HEALTH OF INSTITUTIONALIZED ELDERLY WOMEN IN THE CITY OF FORTALEZA-CE}

\begin{abstract}
Introduction: We know that Brazil, previously referred to as a country of young people, is in the process of demographic transition and presents a rapid population aging, however we face discrimination, and a shortage of proposals aimed at this audience in order to favour autonomy. Objective: To describe the benefits that the practice of dance can provide, as a therapeutic resource, to institutionalized elderly women in the city of Fortaleza / CE. Method: The research that gave rise to this study used an investigation with a qualitative approach, supported by the action research method, carried out in an interventional program in the form of a dance workshop with seven institutionalized elderly women. Semi-structured interviews were carried out, analysed through the operators of the Collective Subject Discourse (DSC) method. Results: Categories were found that reveal that dance provides benefits such as: increased physical disposition to perform activities of daily living, improved pain and the recovery of self-esteem. Conclusions: The data indicate that dance can be an important therapeutic resource for improving the physical fitness of the elderly, thus contributing to healthy aging, encompassing physical and emotional aspects.
\end{abstract}

Keywords: Aging. Dance. Body. Health of the Elderly.

\section{INTRODUÇÃO}

Sabe-se que o Brasil, antes referido como um país de jovens, está em processo de transição demográfica e apresenta um rápido envelhecimento populacional. Esta realidade 
é atribuída ao aumento da expectativa de vida, à redução da taxa de natalidade além de apresentação de melhores condições de vida no País. Conforme uma pesquisa realizada pelo Instituto Brasileiro de Geografia e Estatística (IBGE, 2015), 14,3\% de toda a população é constituído por idosos, correspondendo a 29,3 milhões de pessoas. "Em 2016, a população brasileira foi estimada em 205,5 milhões de pessoas. Entre 2012 e 2016, a população idosa (com 60 anos ou mais de idade) cresceu 16,0\%, chegando a 29,6 milhões de pessoas" (IBGE/PNAD, 2016, p.1). Nesse contexto, a população de mulheres idosas, em especial, encontra-se em crescente aumento. Para o ano de 2050, de acordo com Nascimento (2001), espera-se que $58,4 \%$ de 38,3 milhões de pessoas com 60 anos de idade ou mais no Brasil seja composta por mulheres idosas.

Apesar do envelhecimento ser um processo que ocorre ao longo de toda a vida, a velhice enquanto uma fase do ciclo vital é marcada por estigmas sociais sendo, muitas vezes, associada a limitações, doença, morte e decrepitude (Brito \& Silva, 2017). Por um lado, as mulheres idosas vivenciam um estigma social mais evidente, uma vez que a sociedade contemporânea ocidental exalta a juventude e hipervaloriza a beleza estética. Nesse sentido, o problema "não é a velhice, mas a velhice feia, carcomida, sem movimento, parada, encostada, que não se expõe ao mundo" (Bispo, 2016, p.61).

A realidade vivida pelas idosas no atual contexto da sociedade brasileira ainda revela certas condições de exclusão social. Nesse cenário, destaca-se aqui uma parcela dessa população de mulheres idosas: as que vivem em Instituições de Longa Permanência para Idosos (ILPI). Essas mulheres parecem ser as mais prejudicadas pelas más condições de cuidado com os idosos, sobretudo pelo preconceito social, uma vez que a carência financeira e a falta de moradia estão entre os principais motivos que levam um idoso a recorrer a uma ILPI (Alencar, 2013). Segundo as estatísticas oficiais do IBGE (2013), quase 1,3 milhão de idosos residem em ILPI.

As ILPI, termo adotado pela Sociedade Brasileira de Geriatria e Gerontologia (SBGG) tem a função de auxiliar o idoso, constituindo-se enquanto uma rede de apoio que oferece residência a pessoas desprovidas de cuidadores e em condições financeiras precárias, que necessitam de abrigo e assistência imediata (Brandão \& Zatt, 2015)

A institucionalização em uma ILPI acarreta muitas mudanças na vida do idoso, uma vez que ele passa a ter a sua independência condicionada, podendo ocasionar distúrbios físicos, psicológicos e sociais, como depressão, despersonalização e senso de isolamento (Alencar, 
2013). Nesse sentido, segundo Brandão e Zatt (2015), as ILPIs podem oportunizar ou dificultar a percepção de autonomia e de qualidade de vida pelos idosos residentes.

Além da vivência em uma ILPI com as suas particularidades envolvidas, o idoso ainda se defronta com as mudanças físicas, sociais e psíquicas atreladas ao seu processo de envelhecimento. Tal fato, o convoca a adaptações e ressignificações em muitos aspectos de sua vida (Couto \& Nicolau, 2007).

Em relação à capacidade funcional do corpo idoso, Demontiero, Vidal e Duque (2012) destacam que, após os 50 anos de idade, inicia-se a atrofia óssea o que poderá levar a fraturas. Fechine e Trompieri (2012) evidenciam a perda de massa muscular bem como a diminuição da força muscular, tendo como consequências a redução na mobilidade e o risco aumentado de quedas.

Sobre os aspectos sociais da vida do idoso, destacam-se as alterações no desempenho de papéis que ele assume no seio da sociedade, tais como: a chegada da aposentadoria, a perda de um status social, crises de identidade, dentre outros. Em relação aos fatores psicológicos, destacam-se as atitudes do idoso e as suas formas de adaptação e significação frente a sua história de vida, convocando reajustamentos de si diante do desempenho de novos papéis e novas limitações advindas do próprio envelhecimento (Zimerman, 2007).

Com base nessa realidade, entende-se que as atividades físicas que combatam o sedentarismo, estimulem a integração e a socialização e favoreçam atitudes positivas e o exercício da autonomia são fundamentais para a mulher idosa. Uma vez que o sedentarismo é um fator facilitador de doenças crônico-degenerativas, o combate as posturas sedentárias ocupam um lugar de destaque na Política Nacional de Atenção Integral à Saúde da Mulher (Ministério da Saúde, 2004).

Nesse sentido, uma das alternativas para o combate ao sedentarismo é a prática regular da dança para o público idoso. Um estudo internacional de revisão sistemática de literatura sobre a eficácia da dança enquanto uma proposta de intervenção para a melhoria da saúde em idosos apontou que esta prática propicia uma melhora significativa da força e resistência muscular, da aptidão funcional, do equilíbrio além promover sensação de bem-estar (Hwang \& Braun, 2015). Já um estudo nacional de revisão sistemática de literatura apontou os mesmos benefícios para o público idoso brasileiro, citando ainda a melhoria do desempenho 
cognitivo, a diminuição de dores, aumento da socialização e da percepção de qualidade de vida (Venancio et al., 2018). Além desses fatores, a dança destaca-se por ser uma atividade física extremamente prazerosa e bem aceita pelo público idoso (Bennett, Angel, \& Hackney, 2019).

Assim sendo, a prática da dança, enquanto alternativa de atividade física para idosos, aparece como uma possibilidade de recurso terapêutico para a melhoria da saúde de idosas - não só a dança técnica, mas o movimento expressivo que surge a partir de uma proposta lúdica. Nesse sentido faz-se relevante questionar: quais são os benefícios que a prática da dança, enquanto recurso terapêutico, pode proporcionar a idosas institucionalizadas? Seguindo essa questão, o objetivo deste artigo é descrever os benefícios que a prática da dança, como recurso terapêutico, pode proporcionar a idosas institucionalizadas da cidade de Fortaleza/CE.

\section{PERCURSO METODOLÓGICO}

Este artigo é derivado de uma pesquisa de abordagem qualitativa, de natureza empírica, apoiada no método da pesquisa-ação. A pesquisa qualitativa tem por objetivo descrever e compreender o fenômeno a partir da experiência tal como é vivida e interpretada pelo indivíduo, mediante uma perspectiva que prioriza os significados das ações e das relações humanas (Agee, 2009; Santos, 2017).

Já a pesquisa-ação de acordo com Thiollent (2011), é caracterizada como um tipo de pesquisa social com base empírica, concebida e realizada em estreita associação com uma ação ou com a resolução de um problema coletivo no qual os pesquisadores e os participantes, representativos da situação e/ou do problema, estão envolvidos de forma cooperativa e participativa. Ademais, segundo Engel (2000), a pesquisa-ação busca integrar os processos de pesquisa, formação e reflexão ao contribuir para a construção do saber a partir da prática, reunindo pesquisa e intervenção.

O plano de ação para esta investigação foi elaborado de forma a sustentar um programa interventivo chamado pelos autores de "Vivendo a Terceira Idade", realizado em uma ILPI em Fortaleza/CE. Esse programa incluiu as seguintes etapas: 1) Divulgação da oficina, através de cartazes na instituição: 2) Sensibilização, momento de aproximação e estabelecimento de vínculo com o grupo em formação; 3) Realização de entrevistas semiestruturadas; e 4) Desenvolvimento de uma oficina de dança. Tal estratégia interventiva 
teve periodicidade semanal, realizada durante quatro meses - entre junho e setembro de 2016. A oficina de dança ocorreu às quintas-feiras, de $8 \mathrm{~h}$ às $9 \mathrm{~h} 30$, totalizando 16 encontros. Os dias e horários foram acordados entre os pesquisadores e a direção da instituição, respeitando o cronograma das outras atividades que aconteciam no local.

Participaram da estratégia interventiva três autores, sendo a oficina conduzida pelo primeiro autor do estudo uma vez que sua área de formação acadêmica é fisioterapia com experiência em dança. Já os demais autores auxiliaram na realização das entrevistas e no processo de análise de dados.

As aulas que compuseram a oficina tiveram caráter lúdico-experimental e terapêutico, obedecendo a uma sequência de atividades propostas: roda de conversa inicial ou acolhimento, aquecimento, dança expressiva, relaxamento e roda de conversa final. Essas práticas compreenderam exercícios de alongamento, equilíbrio, exploração do espaço, coordenação motora, consciência corporal, trabalho respiratório, entre outros. Vale ressaltar que as atividades foram devidamente adaptadas à realidade dos sujeitos da pesquisa, dado o seu estado de saúde e a sua fragilidade física.

A partir da imersão em campo, se tornou necessário utilizar o diário de campo como nota para organizar os acontecimentos cotidianos do grupo. Assim, foi possível registrar a fala das idosas, as atividades desenvolvidas, o comportamento de cada uma, além da relação que estabeleciam umas com as outras. Tal registro seguiu em paralelo com a utilização do método da observação participante de investigação qualitativa que segundo Bakeman e Quera (2011) orienta a percepção e observação dos pesquisadores para um registro fidedigno dos fenômenos observados durante a investigação.

Foram incluídas na pesquisa idosas que manifestaram vontade de participar da oficina proposta, concordaram com o Termo de Consentimento Livre e Esclarecido (TCLE) e apresentaram capacidades de marcha, equilíbrio e cognição preservadas, critérios imprescindíveis para a execução satisfatória das atividades propostas e a minimização dos riscos à integridade das participantes. Foram preteridas da pesquisa as idosas que apresentaram limitações de marcha e equilíbrio, déficits cognitivos que afetaram a sua capacidade de compreensão sobre as atividades propostas, e as que não aceitaram participar da oficina ou se recusaram a assinar o TCLE. 
A pesquisa contou com um grupo formado por sete idosas institucionalizadas com idade entre 60 e 86 anos. Esse número reduzido de participantes oportunizou uma melhor integração do grupo e viabilizou a observação participante, bem como as atividades práticas da pesquisa. A seguir, elaborou-se uma tabela (Tabela 1) que sintetiza o perfil sociodemográfico das participantes. Ressalta-se que a fim de preservar as identidades envolvidas, foram atribuídos nomes fictícios às participantes desta pesquisa.

Tabela 1. Perfil Sociodemográfico das Participantes

\begin{tabular}{|c|c|c|c|c|}
\hline $\begin{array}{l}\text { Idosas } \\
\text { participantes }\end{array}$ & Idade & Grau de Escolaridade & $\begin{array}{r}\text { Tempo } \\
\text { na instituição }\end{array}$ & Como aceitou a oficina \\
\hline Fernanda & 82 & $2^{0}$ & grau incompleto & Aceitou bem \\
\hline Graça & 16 anos & & & Aceitou bem \\
\hline Christina & $\begin{array}{l}61 \\
\text { anos }\end{array}$ & Sem instrução institucional & 7 & $\begin{array}{r}\text { Resistente no começo, aceitou } \\
\text { bem depois }\end{array}$ \\
\hline Roberta & 60 & Sem instrução institucional & 3 & Aceitou receosa \\
\hline Greyce & anos & & & Aceitou bem \\
\hline Renata & & & & Aceitou bem \\
\hline \multirow[t]{4}{*}{ Ana } & $\begin{array}{l}86 \\
\text { anos }\end{array}$ & 1ํgrau completo & 10 & $\begin{array}{r}\text { Resistente, mas } \\
\text { participou }\end{array}$ \\
\hline & $\begin{array}{l}70 \\
\text { anos }\end{array}$ & $2^{\circ}$ grau completo & 2 & \\
\hline & $\begin{array}{l}80 \\
\text { anos }\end{array}$ & Sem instrução institucional & 4 & \\
\hline & $\begin{array}{l}68 \\
\text { anos }\end{array}$ & $1^{\circ}$ grau completo & 6 & \\
\hline
\end{tabular}

Vale ressaltar que o lócus da pesquisa foi uma instituição sem fins lucrativos de utilidade pública que, no período da investigação, abrigava 48 idosas. Algumas delas possuíam vínculos familiares ativos e recebiam visitas; outras, porém, não recebiam visitas devido a um paradeiro familiar desconhecido. Esta instituição foi selecionada para a pesquisa pelo fato de acolher idosas que se encaixavam nos critérios de inclusão dos sujeitos deste estudo, e também por apresentar extrema carência de recursos, desde os mais básicos itens de higiene até a assistência profissional adequada.

Esta ILPI, apesar da carência de recursos, assegura às idosas - muitas vezes com trabalhos voluntários ou parcerias com instituições de nível superior - a prestação dos seguintes serviços: fisioterapia, terapia ocupacional, terapia com cães, psicologia, dança sênior e contação de histórias. Além dos serviços prestados, são organizados encontros festivos nas principais datas comemorativas: Dia das Mães, Semana do Idoso, Páscoa, Natal e Ano Novo. 
Após a realização de um questionário sociodemográfico, foram realizadas as entrevistas semiestruturadas de caráter individual em paralelo ao período da execução da oficina de dança proposta. As entrevistas obtiveram duração média de 40 minutos, foram gravadas para posterior registro fidedigno dos dados coletados e realizadas em local reservado, cedido pela ILPI, na qual foi realizado o estudo. A entrevista semiestruturada individual, como instrumento de coleta de dados, justificou-se pela possibilidade de o entrevistado discorrer livremente sobre o tema em questão e o entrevistador poder realizar, então, novas perguntas sem a necessidade de se ater a um questionário rigidamente formulado (Duarte, 2004).

As entrevistas em questão foram constituídas pelas seguintes perguntas norteadoras: "A senhora considera que a dança tem trazido benefícios para a sua rotina?" e "Quais os benefícios observados?". Os dados coletados foram gravados e transcritos na íntegra, pelos autores do estudo, e analisados com base na técnica do Discurso do Sujeito Coletivo (DSC) (Lèfreve \& Lèfreve, 2010).

Para a categorização dos discursos, foi utilizado o Instrumento de Análise de Dados 1 (IAD1) descrito pelo DSC, que consiste na seleção das expressões-chave (ECH: trechos literais contínuos ou descontínuos do discurso que denotam o que há de mais significativo e essencial nas respostas ) e das ideias centrais (IC: expressões que nomeiam e descrevem, de modo mais sintético e preciso possível, o significado presente em cada conjunto de ECH das respostas analisadas) correspondentes a cada discurso. Nesse sentido, as categorias de análise se deram a partir do agrupamento das ideias centrais, que se originaram a partir das respectivas expressões chaves que apresentavam um padrão de significados semelhantes (Lèfreve \& Lèfreve, 2010).

Para uma maior credibilidade, a estratégia de validação da análise de dados utilizada foi o método de comparação constante entre os pesquisadores a fim de se chegar em um acordo e consenso em relação aos resultados. Além disso, realizou-se o critério da reflexividade no transcurso da investigação. Tais procedimentos estão de acordo com as indicações dos critérios de validade e confiabilidade em pesquisa qualitativa segundo Manzano-Arrondo (2019).

Vale mencionar ainda que esta pesquisa contou com a aprovação do Conselho de Ética em Pesquisa (CEP), sob o parecer $n^{\circ} 1.715 .149$ da Universidade de Fortaleza (UNIFOR), assegurando, assim, a realização de uma prática de pesquisa eticamente responsável, 
respaldada pela Resolução no 466, de 12 de dezembro de 2012, do Conselho Nacional de Saúde (CNS).

\section{RESULTADOS E DISCUSSÃO}

A ação da pesquisa se consolidou pela oficina de dança proposta, pelo diário de campo dos pesquisadores e pelos relatos obtidos nas entrevistas semiestruturadas. A análise dos dados coletados revelou três categorias de discurso: Disposição, Melhora dos quadros álgicos e Melhora da autoestima (conforme sintetizado no Quadro 1).

Quadro 1. Categorias que indicam os benefícios apontados pelas idosas.

\section{Expressões-chave (trechos relevantes) Ideias centrais Categorias}

Fernanda: "Eu gosto de tudo que tem aqui, mas com a dança me sinto mais disposta durante o dia".

Greyce: "Depois que comecei as aulas de dança não canso tanto quando faço caminhada (...) Depois que comecei a dançar, faço as minhas caminhadas diárias e sinto menos cansaço".

Renata: "Melhorei da dor que sinto nas pernas e pés".

Roberta: "Parece até que cresci... Consigo sentar melhor, antes doía tudo aqui nas costas".

Christina: "Melhorou foi a dor que sentia nas costas, lavo

Percepção de melhora das dores

realização das
atividades

Disposição minha roupa todinha".

Graça: "Agora eu gosto mais de passar batom".

Renata: "Eu me sinto mais bonita, né... Eu acho que eu me cuido mais".

Greyce: "Agora eu me arrumo mais, me olho mais no espelho, passo batom..."

Melhora da auto- estima

A sensação de maior disposição foi uma categoria encontrada no discurso de Greyce e Fernanda. Tais idosas demonstraram bastante disposição física durante a realização dos exercícios e movimentos propostos, os executando com facilidade e desenvoltura. Em seus relatos, mencionaram ainda sentirem-se mais dispostas para a realização de suas atividades diárias após o início da oficina de dança. Segundo Greyce, "Depois que comecei a dançar, faço as minhas caminhadas diárias e sinto menos cansaço". Já Fernanda comentou: "Eu gosto de tudo que tem aqui, mas com a dança me sinto mais disposta durante o dia".

Durante a realização da oficina, Fernanda se mostrou sempre ativa e participativa. Nas últimas aulas, ela relatou que estava disposta todo dia e que seu vigor havia aumentado 
sensivelmente. Assim como Fernanda, Greyce comentou: "Depois que comecei as aulas de dança, não canso tanto quando faço minhas caminhadas". A partir desses dois relatos e das observações feitas em campo, verifica-se que as aulas de dança favoreceram a rotina das idosas na realização de suas atividades funcionais.

Nessa perspectiva, o aumento da disposição e do condicionamento físico testemunhado pelas idosas pode estar relacionado com alguns benefícios físicos acarretados pela prática regular da dança. Tal atividade física pode propiciar ao idoso a melhora da aptidão musculoesquelética e cardiorrespiratória, da resistência, da força muscular e da flexibilidade, além de fortificar a capacidade motora - a coordenação de movimentos, o equilíbrio, a agilidade e a potência muscular, sendo ainda uma atividade lúdica prazerosa bem aceita pelo público idoso (Silva, Martins, \& Mendes, 2012).

No contexto das idosas institucionalizadas, a sensação de desamparo pode acarretar "um comportamento dependente em diferentes graus, devido à dificuldade na aceitação e adaptação das novas condições de vida, sendo comuns a desmotivação e o desencorajamento" (Marchon, Cordeiro, \& Nakano, 2010, p. 204-205). Por isso, a dança pode ser uma alternativa de estímulo à autonomia e independência do idoso em ILPI, a fim de manter ou fomentar sua capacidade funcional - suas habilidades físicas e mentais - para uma vida mais potente, realizando um bom desempenho nas tarefas e ações da vida cotidiana (Silva \& Berbel, 2015).

Sob essa perspectiva, a prática regular da dança favorece a prevenção de doenças crônicas e contribui para a diminuição do sedentarismo em idosos que vivem em ILPI. Assim sendo, "é através da dança, que é uma atividade física bem divertida de ser praticada, que muitos podem viver e alcançar uma determinada idade com boa saúde e muita disposição" (Marbá, Silva, \& Guimarães, 2016, p. 3).

Outra categoria revelada nos discursos se refere à melhoria dos quadros álgicos, mencionada pelas idosas Renata, Roberta e Christina. Todas elas possuíam queixas frequentes de dores, mas, durante a oficina, relataram perceber melhoras físicas e até mesmo a ausência de dores. No caso delas, o quadro álgico foi instalado pelas condições degenerativas provenientes do envelhecimento, agravadas pelo sedentarismo e pelos sentimentos de abandono e confinamento comuns em idosos institucionalizados. Durante a oficina, observou-se que a diminuição das dores favoreceu ainda outros aspectos, como o bem-estar e a disposição diária. 
Efetivamente, o processo de envelhecimento pode ocasionar declínios na aptidão física do idoso, e o quadro se agrava ainda mais com o sedentarismo, tornando os idosos dependentes de cuidados de outrem. Observa-se que tal situação prevalece mais entre os indivíduos institucionalizados, tornando-os portadores de várias doenças decorrentes da inatividade (Mazo et al., 2011). Um estudo realizado por Reis e Torres (2011) aponta que o idoso institucionalizado possui nove vezes mais chances de sofrer quedas que o idoso que mora na comunidade. Além disso, foi identificada a presença de dores em $73,3 \%$ dos idosos institucionalizados participantes da pesquisa, majoritariamente devido à ocorrência de doenças osteomusculares.

Conforme relatado pelas idosas Renata, Roberta e Christina, a dança proporcionou o alívio de seus quadros álgicos, o que favoreceu a melhora da disposição física dessas idosas. Nesse sentido, podemos compreender que a prática regular da dança em idosos pode trazer vários benefícios possíveis, tais como atenuar patologias e "prevenir o declínio cognitivo, melhorar a autoestima, a coordenação, a memorização, o equilíbrio, a força muscular, a potência aeróbia e diminuir o risco de quedas na terceira idade" (Tonon, Duim, \& Santos, 2012, p. 519).

Renata afirmou que a dor que sentia nas pernas e nos pés melhorou com os exercícios propostos pela oficina. Já Roberta discorreu sobre a sensação de mobilidade do corpo, observando que ela passou a conseguir sentar-se sem sentir dores, demonstrando, assim, os benefícios dos exercícios de alongamento e mobilização articular propostos na oficina. Tal percepção sobre a melhoria dos quadros álgicos foi bastante recorrente entre as idosas no momento da realização das rodas de conversa além de ser perceptível a melhora de disposição física frente a execução dos exercícios propostos durante a realização da oficina.

Para além desses fatores, constatou-se que, no decorrer das intervenções, as idosas passaram a apresentar mais facilidade na execução de movimentos funcionais, como na deambulação, nas mudanças de posições - da posição sentada para a posição de pé -, no equilíbrio e em outros aspectos. Nesse sentido, diante dos relatos e da observação participante, foi percebido que a dança proposta estimulou o movimento das estruturas osteomioarticulares das idosas, contribuindo para a melhoria da sua postura, do equilíbrio, da respiração e da circulação, propiciando assim o alívio das dores.

Já a terceira categoria revelada pelos discursos faz menção ao aumento da autoestima. As idosas Graça, Renata e Greyce discorreram sobre a mudança da percepção positiva de si 
mesmas, estimuladas através do autocuidado. Observou-se que, no decorrer da oficina de dança, as idosas em questão se permitiram fazer penteados no cabelo e usar batom e maquiagem. Ademais, os sorrisos passaram a ser mais presentes. Para Graça, um dos maiores benefícios revelados na prática da dança foi o fato de "perceber a si mesma" e sentir-se mais bonita: "passei a gostar de passar batom", como ressaltado por ela. Greyce e Renata testemunharam de forma semelhante, afirmando se sentirem mais vaidosas e se observarem mais no espelho depois que começaram a dançar.

Esses relatos parecem revelar que a dança pode promover o aumento da autoestima em idosas institucionalizadas além de possibilitar a integração e socialização dessas mulheres, oportunizando momentos de prazer e felicidade. Pode-se considerar, portanto, que a dança pode proporcionar vitalidade, satisfação, sensação de bem-estar subjetivo além de melhorar a capacidade cognitiva (Sawami et al., 2019). Nesse sentido, "essa prática de atividade leva o indivíduo a ter mais motivação, autoestima e autodeterminação" (Marbá, Silva, \& Guimarães, 2016, p. 3).

Percebeu-se ainda que todas as participantes sinalizaram posturas de autocuidado e resgate da sua feminilidade, favorecendo o desenvolvimento de uma autoimagem positiva. Elas passaram a sentir mais confiança e segurança em si mesmas e a redescobrir suas belezas, aspectos constatados através dos relatos e das observações em campo. Assim, o aumento da autoestima evidenciou-se enquanto mais um benefício oportunizado pela prática da dança para as idosas institucionalizadas.

\section{CONSIDERAÇÕES FINAIS}

De acordo com as categorias reveladas e discussões propostas neste artigo, é possível inferir que a dança pode ser utilizada como um recurso terapêutico capaz de propiciar benefícios que dizem respeito aos aspectos físicos e emocionais para o público de idosas institucionalizadas. Essa consideração é fruto das entrevistas e das observações participantes no contexto do grupo específico investigado.

A dança, nessa perspectiva, aparece como uma das possibilidades de se vivenciar a velhice com mais qualidade de vida. De acordo com as categorias discutidas, a inserção da dança na rotina da mulher idosa institucionalizada proporcionou os seguintes benefícios: melhoria da capacidade motora, articular, muscular e cardiorrespiratória, permitindo assim o aumento da disposição e do condicionamento físico; melhoria dos quadros álgicos; sensação de bem- 
estar corporal; maior capacidade de realização das atividades da vida diária; melhoria do equilíbrio e da postura corporal; maior amplitude de movimentos; e aumento da coordenação motora.

No que tange aos benefícios emocionais, destaca-se que a prática da dança possibilitou o aumento da autoestima das idosas em questão e, com ela, uma percepção mais positiva de si. Foi observado também o fato de que a dança desenvolveu aspectos que envolvem autonomia e autocuidado, além de ter proporcionado momentos de diversão e socialização para o grupo, o que favorece a sensação de bem-estar subjetivo.

Além desses benefícios, a dança parece oportunizar a amplitude do repertório de movimentos e o início de um rompimento de padrões rígidos desenvolvidos e mantidos pelo corpo em seu dia a dia, que pela repetição, parece ter esquecido sua plasticidade e espontaneidade tão significativa para a expressão de si através do corpo. Assim sendo, compreende-se que desautomatizar o corpo através da dança é permitir lançar-se para além da zona de conforto e construir uma postura de revolução ao rever e ampliar conceitos sobre si mesmo e sobre o mundo, isto é, se redescobrir e recriar para si condições de apropriação do seu sentido de existência, bem-estar, liberdade, autonomia e potência de vida. Percurso esse iniciado pelas idosas em questão ao permitirem-se dançar, revelando benefícios de âmbitos físicos e psicossociais.

Portanto, acredita-se que este estudo possa contribuir para a construção de possibilidades terapêuticas inovadoras direcionadas para o público idoso - possibilidades que visam à ludicidade, à criatividade e à humanização, pautadas no bem-estar físico, social e emocional desses sujeitos.

Vale ressaltar ainda a importância da utilização de abordagem qualitativa uma vez que esta permite os pesquisadores enfocarem-se nas percepções e experiências dos sujeitos participantes por meio de seus discursos, colhido nas entrevistas com suas impressões pessoais e genuínas mediante a imersão das idosas em questão no projeto interventivo de pesquisa-ação desenvolvido. 


\section{REFERÊNCIAS}

Agee, J. (2009). Developing qualitative research questions: a reflective process. International Journal of Qualitative Studies in Education, 22(4), 431-447.

Alencar, I. (2013). O vínculo familiar dos idosos de uma Instituição de Longa Permanência. (Monografia, Faculdade de Assistência Social, Universidade Católica de Brasília).

Bakeman, R., \& Quera, V. (2011). Sequential analysis and observational methods for the behavioral sciences. Cambridge, England: Cambridge University Press.

Bennett, C., Angel, N., \& Hackney, M. (2019). Mismatch between subjective and objective motor improvements with adapted tango intervention in older adults. Innovation in Aging, 3(1), 156-170.

Bispo, R. (2016). ¿Beleza eterna? A experiência de envelhecimento entre dançarinas eróticas "das antigas". Revista Latinoamericana de Estudios sobre Cuerpos, Emociones y Sociedad, 8(21), 52-63.

Brandão, V. C., \& Zatt, G. B. (2015). Percepção de idosos, moradores de uma instituição de longa permanência de um município do interior do Rio Grande do Sul, sobre qualidade de vida. Aletheia, (46), 90-102.

Brito, J Q. A., \& Silva, Olga M. (2017). O avanço da estética no processo de envelhecimento: uma revisão de literatura. Id on Line Multidisciplinary and Psycology Journal, 11(35), 424-440.

Couto, J. P. A. do., \& Nicolau, R. A. (2007). Estudo do envelhecimento da derme e epiderme - revisão bibliográfica. In Encontro Latino Americano de Pós-graduação. Universidade do Vale do Paraíba, Brasil.

Demontiero, O; Vidal, C., \& Duque, G. (2012). Aging and bone loss: new insights for the clinician. Therapeutic Advances in Musculoskeletal Disease, 4(2), 61-67.

Duarte, R. (2004). Entrevistas em pesquisas qualitativas. Educar em Revista, (24), 213-225.

Engel, G I. (2000). Pesquisa-ação. Educar em Revista, 16(16), 181-191.

Fechine, B., \& Trompiere, N. (2012). O processo de envelhecimento: as principais alterações que acontecem com o idoso com o passar dos anos. Revista Científica Internacional, 20(1), 115-121.

Hwang, P. W., \& Braun, K. L. (2015). The Effectiveness of Dance Interventions to Improve Older Adults' Health: A Systematic Literature Review. Alternative therapies in health and medicine, 21(5), 64-70.

Instituto Brasileiro de Geografia e Estatística. (2013). Séries Estatísticas e Séries Históricas. Brasília: IBGE.

Instituto Brasileiro de Geografia e Estatística. (2015). Pesquisa Nacional por Amostra de Domicílios. Rio de Janeiro: IBGE.

IBGE/PNAD. (2016). Portal do Instituto Brasileiro de Geografia e Estatística/ Pesquisa Nacional por Amostra de Domicílios. Retrieved from: https://agenciadenoticias.ibge.gov.br/agencia-noticias/2013-agencia-denoticias/releases/18263-pnad-2016-populacao-idosa-cresce-16-0-frente-a-2012-e-chega-a-29-6milhoes.html

Lèfevre, F.,\& Lèfreve, A. (2010). Pesquisa de representação social: um enfoque qualiquantitativo. Brasília: Líber Livro.

Marbá, R. F; Silva, G. S. da.,\& Guimarães, T. B. (2016). Dança na promoção da saúde e melhoria da qualidade de vida. Revista Científica do ITPAC, 9(1), 1-9.

Manzano-Arrondo, V. (2019). La X Cualitativa Construcción de ciencia para gente valiente [PDF]. Retrieved from: http://asignatura.us.es/mcualitativa/mec/ManLibro.4.pdf 
Marchon, R. M., Cordeiro, R. C., \& Nakano, M. M. (2010). Capacidade Funcional: estudo prospectivo em idosos residentes em uma instituição de longa permanência. Revista Brasileira de Geriatria e Gerontologia, 13(2), 203-214.

Mazo, G.Z., Silva, A. H. da., Gonçalves, L. T., Benedetti, T. B., Claudino, R., \& Benetti, M. Z. (2011). Aptidão física de idosos institucionalizados: um estudo interinstitucional. ConScientiae Saúde, 10(3), 473-479.

Ministério da Saúde. (2004). Política nacional de atenção integral à saúde da mulher: princípios e diretrizes. Brasília: Editora MS.

Nascimento M. R. (2001). Feminização do envelhecimento populacional: expectativas e realidades de mulheres idosas quanto ao suporte familiar. In $\mathrm{L}$ Wong (org.). O envelhecimento da população brasileira e o aumento da longevidade. Subsídios para políticas orientadas ao bem-estar do idoso (pp. 191-218). Belo Horizonte: Editora CEDEPLAR-UFMG-ABEP.

Reis, L. A., \& Torres, G. D. V. (2011). Influência da dor crônica na capacidade funcional de idosos institucionalizados. Revista Brasileira de Enfermagem, 64(2), 274-280.

Santos, C. F. (2017). Uma abordagem sobre pesquisa qualitativa. Revista Facthus de Administração e Gestão, 1(2), 116-125.

Sawami, K., Kimura, M., Kitamura, T., Kawaguchi, M., Furusumi, M., Suishu, C., Morisaki, N., \& Hattori, S. (2019). Cognitive ability and psychological effectiveness of brain training dance robot therapy for elderly people. $O A$ Journal of Neuropsychiatry, 1, 1-7.

Silva, A. F. G., \& Berbel, A. M. (2015). O benefício da dança sênior em relação ao equilíbrio e às atividades de vida diárias no idoso. ABCS Health Sciences, 40(1), 16-21.

Silva, F. J., Martins, L., \& Mendes, C. (2012). Benefícios da Dança na terceira idade. In IV Seminário de Pesquisas e TCC. Faculdade União de Goyazes, Goiás, Brasil.

Silva, O M, \& Brito, J Q. (2017). O Avanço da Estética no Processo de Envelhecimento: Uma Revisão de Literatura. Revista Multidisciplinar e de Psicologia. 11(35), 424-440.

Thiollent, M. (2011). Metodologia da pesquisa-ação. São Paulo: Cortez.

Tonon, P. P., Duim, E. L., \& Santos, S. S. (2012). Efetividade da Fisioterapia Associada à Dançaterapia na Melhora da Capacidade Aeróbia e Flexibilidade de Mulheres Idosas com Histórico de Quedas. Saúde e Pesquisa, 5(3), 87-98.

Venancio, R.C. de P., Carmo, E. G. do., Paula, L. V. de., Schwartz, G. M., \& Costa, J. L. R. (2018). Efeitos da prática de Dança Sênior® nos aspectos funcionais de adultos e idosos. Cadernos Brasileiros de Terapia Ocupacional, 26(3), 668-679.

Zimerman, G. (2007). Velhice: aspectos biopsicossociais. Porto Alegre: Artmed. 